\title{
Sliding Factor Development on Mechanical Emotion in Mobile Phone of Slide Type
}

\author{
Jaein Lee ${ }^{1}$, Jungwoong Byun ${ }^{1}$, Jaehwa Jeong ${ }^{2}$, C. J. Lim \\ ${ }^{1}$ Production Research Institute, LG Electronics, Pyeongtaek, 451-713 \\ ${ }^{2}$ Department of Control and Instrumentation Engineering, Korea University, Sejong City, 339-700 \\ ${ }^{3}$ Department of Game and Multimedia Engineering Korea Polytechnic University, Shihung, 429-793
}

\begin{abstract}
Objective: The aim of this study is to find the optimal values of sliding factors which influence the mechanical emotion of users when they use sliding type mobile phones. Background: There are various researches that study the emotion of using mobile phones. They focus the correlation between emotion words and design factors and use the commercial products by the subjects in the experiment. However, it has a limit in finding the optimal point of emotional factors because we can search the restricted values in the mass production of the products. Therefore, we will find the optimal points by realizing the full range of the user's mechanical emotion. Method: First, we need to get the detailed factors which can describe the mechanical emotion in sliding up and down the mobile phone. Next, we find the control factors by considering the correlation between the factors of the sliding emotion and the possibility of quantitative design. To find the optimal points on the control factors, we make a sliding evaluation system which can help users feel the sliding mechanical emotion by realizing control factors. Finally, we find the optimal points by doing the experiment the system being used. Results: The critical values of the factors which are the main variables of this study are Open Max Force and Dead point Ratio. The optimal point of the Open Max Force is 200 250g/f, and the Dead point Ratio is 40 50\%. Conclusion: In this study we develop the sliding evaluation system to realize the control factors of the sliding type phone and find the optimal values of the critical factors. Application: The results can be used as the criteria for designing sliding type phone.
\end{abstract}

Keywords: Sliding force, Sliding system, User emotion satisfaction, Breakpoint, Slide type phone

\section{Introduction}

새로운 제품에 대한 소비자의 욕구는 소비자 자신의 제품 사용 경험과 의식뿐만 아니라 그 제품을 공급하는 생산자들 의 기술 및 디자인 능력과 서로 상호작용을 하며 변화한다 (Koohyoung Lee, 2000). 소비자들은 특정 제품을 구매하 고자 할 때, 다양한 관점에서 대안 제품을 평가하고 그 가운 데서 최적이라고 판단하는 제품을 선택하게 된다(Min woO
Hwang et al., 2007). 이러한 제품 선택 시 소비자들은 제품 의 물리적 속성이나 기능에 대한 이성적 판단 요소보다는 제품의 외형적 느낌이나 사용 중 편리성 등 총체적 느낌이 나 제품 주변에서 인식되는 외적 환경 같은 감성적 요인에 더 많은 영향을 받게 되었다. 즉, 소비자의 감성이 제품의 구매나 소비에 미치는 영향이 커지게 된 것이다(Min woo Hwang et al., 2007). 기업에서는 기존의 이성적인 제품 요 소, 즉 기능적 측면, 가격적 측면 등을 기본으로 함은 물론이 고 감성적 디자인, 감성적 마케팅, 제품 자체의 감성적 기능

Corresponding Author: Jaein Lee. Production Research Institute, LG Electronics, Pyeongtaek, 451-713.

Mobile: +82-10-6899-7516, E-mail: inibest@naver.com

Copyright@2012 by Ergonomics Society of Korea(pISSN:1229-1684 eISSN:2093-8462). All right reserved.

(c) This is an open-access article distributed under the terms of the Creative Commons Attribution Non-Commercial License(http://creativecommons.org/licenses/by-nc/3.0/), which permits unrestricted non-commercial use, distribution, and reproduction in any medium, provided the original work is properly cited. http://www.esk.or.kr 
등 감성적 요인도 중요하게 생각하게 되었다. 이에 기업은 소비자의 감성을 고려한 제품을 만들어 제품을 차별화 시키 고자 노력한다.

이런 배경하에 휴대폰에 대하여 느낄 수 있는 다양한 감성 을 고려한 제품 개발에 대한 연구도 이뤄지고 있다(Myung Hwan Yun et al., 2003). Kim IK et al. (2006)는 휴대폰의 고급감을 평가할 수 있는 다양한 감성 모델링 기법들을 비교 하였다. Sang Hoon Jeong (2008)은 휴대폰 사용 중 표출되 는 사용자의 감성을 평가해 보았다. 그리고 Sang Woo Ban et al. (2010)는 휴대폰의 디자인 요소로서 차별적 경쟁력이 어느 정도 한계에 다다른 상황에서 사용 중 느낄 수 있는 기구적인 감성 요소로서 차별성을 가질 수 있다고 하였다. Min Soo Kim et al.(2006)는 휴대폰의 초기 설계에서 형태 인자 선정의 체계적이고, 합리적 방안을 제시하고자, 감성 형용사를 이용하는 평가 방법론을 제안하였다. 기구적 감성 은 Koohyoung Lee(1998)에서 제시된 제품의 감성 분류인 기능적 감성, 감각적 감성, 사회문화적 감성 가운데서 기능 적 감성에 해당한다(Jang Woo Jung, 2010). Jang Woo Jung (2010)에 따르면 기능적 감성은 기구 감성, Graphic User Interface, Physical User Interface로 구분할 수 있 다. 이 기구 감성에는 휴대폰을 조작할 때 물리적으로 느낄 수 있는 다양한 감성이 포함된다. Touch, Grip, Click, Slide, Fold 등이 해당된다.

본 연구에서는 이러한 기구 감성 가운데서 슬라이드 감성 을 대상으로 한다. 즉, 슬라이드 형태의 휴대폰을 사용할 때 사용자가 느낄 수 있는 슬라이드 감성에 영향을 미치는 요인 을 발굴하고 그것의 최적값을 개발하고자 한다. 특히, 최근 스마트폰이 많이 개발되면서 스마트폰에 적용되는 Qwerty 자판 형태의 슬라이드폰을 주 대상으로 한다. 이로부터 Qwerty 자판을 사용하기 위하여 슬라이딩을 할 때 그 느 낌을 최적화하는 것이다.

\section{Definition}

본 연구에서 나타나는 다양한 용어들에 대한 정의를 먼저 하고자 한다. 이 정의는 본 연구 내에서 한정될 수도 있다.

1) 슬라이드폰(Slide type's mobile phones): 뚜껑(상판) 을 위나 아래로 밀어서 열 수 있는 휴대 전화.

2) 일반 슬라이드폰: 일반적인 휴대폰의 $\operatorname{Keypad}(3 * 4$ 배 열) 가 내장되어 있는 슬라이드폰(Figure 1).

3) Qwerty 슬라이드폰: Qwerty Type의 Keypad가 내장 되어 있는 슬라이드폰(Figure 2).

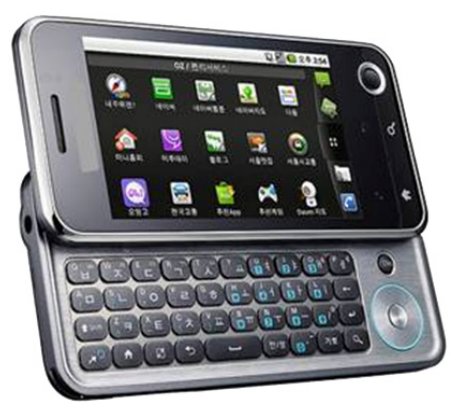

Figure 1. Normal slide phone

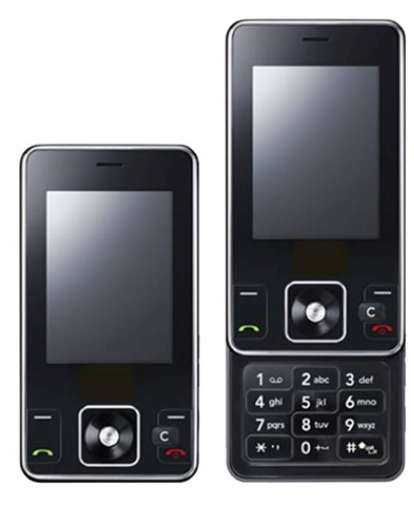

Figure 2. Qwerty slide phone

4) 슬라이딩 (Sliding): 슬라이드폰을 사용하기 위하여 상판 을 밀어 올리는 동작

5) 슬라이드 조작감: 손으로 슬라이딩을 수행할 때 손으로 느낄 수 있는 감성을 통칭함. 상판을 밀어 올리는 느낌, 상판을 밀어 내리는 느낌, 슬라이딩 시 마찰감 등이 있다.

6) 감성 영향 Factor: 슬라이딩 조작감 만족도에 직간접으 로 영향을 미칠 수 있는 제품의 물리적인 Factor. 슬라 이딩 시 손에 걸리는 부하를 나타내는 다양한 Factor들, 즉 열기 시작하는 순간의 힘, 열리는 동안의 최대힘 등 이 해당된다. 또한 폰 크기, 무게, 두께 등도 해당될 수 있다.

7) Breakpoint: 사용자가 느낄 수 있는 사용 중 감성 만족 도를 최대로 하는 최적점. 예를 들면, 슬라이딩을 수행할 때 손에 걸리는 힘이 너무 커도 만족도가 떨어지고, 너 무 적게 들어도 헐거운 느낌에 의해 만족도가 떨어질 수 있다. 이 때 만족도를 최대로 하는 적절한 중간 힘이 Breakpoint이다.

8) Sliding force graph \& force factor

8.1) Sliding force graph

Mecmesin사의 Linear Force Sensor를 수평이송장치 에 장착한 Sliding Force 측정 장치를 활용하여 Sliding 
Force를 측정하고 그 결과를 그래프로 나타낸 것이다 (Figure 3) X축은 상판이 움직이는 거리로서 단위는 $\mathrm{mm}$ 이다. Y축은 상판이 움직일 때 걸리는 부하로서 단위는 $\mathrm{g} / \mathrm{f}$ 이다.

8.2) Open Max Force (OMF)

상판이 열리기 시작한 후 자동으로 밀려 올라가기 전까 지 걸리는 부하의 최대값(Figure 3).

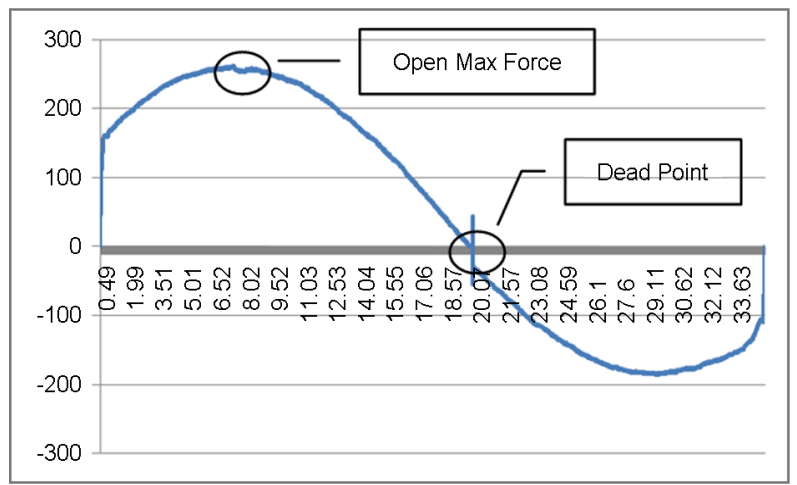

Figure 3. Sliding force garph

\section{3) Dead point}

상판이 열리기 시작한 후 자동으로 밀려 올라가는 지점으 로서 밀어 올리는 사용자의 손에 걸리는 힘이 0가 되는 지점(Figure 3).

8.4) Dead Point Ratio (DPR)

시작점 (상판이 완전히 닫힌 상태)에서 상판이 움직일 수 있는 전체 길이 대비 시작점에서 Dead Point까지의 길 이 비율. 휴대폰마다 전체 길이가 다르기 때문에 Dead Point만으로는 비교가 어려우므로 Dead Point Ratio로 상대비교를 함.

9) 슬라이딩 평가 시스템: 다양한 슬라이드폰에서 느낄 수 있는 Force Factor를 직접 구현하고 그것들 가운데서 가장 선호되는 값을 찾기 위하여 제작된 시스템(4.4 Evaluation System Development 참고).

\section{Method}

본 연구는 슬라이드폰을 사용할 때 느낄 수 있는 최적의 슬라이드 조작감을 구현할 수 있도록 슬라이드 설계 시 반영 할 최적 설계값을 도출하고자 한다. 이를 위하여 다음과 같 은 방법으로 진행된다.

\subsection{Sliding emotion extraction}

슬라이드 조작감에 영향을 미치는 기구적 설계 요소인 감 성 영향 factor를 도출하기 위하여, 슬라이드 조작 감성을 Factor와 연계될 수 있도록 세부 감성들로 분류한다.

\subsection{Detailed emotion extraction}

3.1 에서 세분화된 감성들과 전체 슬라이드 조작 감성 간 의 영향도 분석을 위하여 회귀 분석을 실시한다. 이를 통해 다양한 세부 감성 가운데서 슬라이드 조작 감성에 유의한 영 향을 미치는 세부 감성을 도출한다. 또한, 유의한 영향을 미 치는 세부 감성 가운데서 유의성이 크고 정량적 설계 요소 로 변환이 가능한 세부 감성을 선정하였다.

\subsection{Effect factor extraction and measurement}

이 세부 감성과 관련이 있고 정량적인 설계 요소 변환이 가능한 Factor를 도출하였다. 또한 이 Factor의 대략적인 설계값을 파악하기 위하여 기존의 개발된 슬라이드폰들의 Factor 값을 측정하였다.

\subsection{Evaluation system development}

이 Factor들에 대한 최적의 Breakpoint를 도출하기 위하 여 Factor를 다양하게 구현하여 실제 User가 느낄 수 있게 해주는 시스템을 개발하였다.

\subsection{Optimal value extraction}

평가 시스템을 활용한 평가 실험을 통해 최적의 point를 도출하였다.

\section{Experiment}

\subsection{Sliding emotion extraction}

슬라이드폰의 상판을 슬라이딩할 때 손으로 느낄 수 있는 감성으로 정의한 슬라이드 조작감을 사용자 관점에서 구체 화하기 위해 슬라이드폰 사용자 10명 (남 5, 여 5)을 대상으 로 Brain Storming을 하였다. 이들의 평균 연령을 27.6세였 다. 이 과정을 통하여 다양한 슬라이드 감성을 도출하였고 공통적인 감성으로 분류한 결과, 다음과 같은 6 개의 세부 감 성을 도출하였다. 
[1] 열 때 힘의 느낌

[2] 내릴 때 힘의 느낌

[3] 밀려 올라가기 시작하는 시점(사점 위치) 느낌

[4] 사점 이후 튕겨 올라가는 힘의 느낌

[5] 상판과 하판 간 마찰의 느낌

[6] 열 때 완전히 열리는 순간의 느낌

\subsection{Detailed emotion extraction}

6개의 세부 감성들 가운데서 전체 슬라이드 조작감에 유 의한 영향을 미치는 감성을 파악하기 위하여 실제 슬라이드 폰을 조작하면서 그 만족도를 전체 슬라이드감과 세부 감성 들에 대하여 평가하는 실험을 수행하였다.

총 31 대의 슬라이드폰을 대상으로 평가하였다. 실험에는 총 120 명이 참석하였다. 본 실험에서는 평가 Data의 정규성 확보를 위하여 1 대의 슬라이드폰 당 30 명 정도가 평가한다 는 기준을 지키고자 하였다. 그러면서 1 명이 31 대의 폰을 모두 평가할 경우 정신적인 부하로 인하여 평가에 어려움을 겪을 수 있고 그 결과에 대한 신뢰도도 떨어질 수 있으므로 1 명 당 7 8대 정도만 평가토록 하였다. 즉, 120 명이 모두 각 31 대를 평가한 것이 아니라 4 개 그룹으로 나뉘어 그룹 당 30명씩, 7 대 또는 8대의 폰을 평가한 것이다.

그 평가 결과를 확인하기 위하여, 전체 슬라이드감을 종속 변수로 하고 각 세부 감성을 독립 변수로 한 회귀 분석을 실시하였다. 그 결과 equation (1)과 같이 [1] 열 때 힘의 느낌, [3] 밀려 올라가기 시작하는 시점(사점 위치) 느낌, [5] 상판과 하판 간 마찰의 느낌, [6] 열 때 완전히 열리는 순간의 느낌 등 4 개의 세부 감성이 전체 슬라이드감에 유의 하게 영향을 미치는 것으로 나타났다.

The regression equation $=0.0700+0.485 *[1]+$

$0.208 *[3]+0.178 *[5]+0.125 *[6]$

$[\mathrm{S}=0.708836 \quad \mathrm{R}-\mathrm{Sq}=73.4 \% \quad \mathrm{R}-\mathrm{Sq}(\operatorname{adj})=73.3 \%]$

\subsection{Experiment emotion \& factor extraction}

세부 감성 도출 실험에서 도출된 4 개의 세부 감성 가운데 서 상대적으로 영향도가 높으면서 ([1], [2] > [3], [4]), 실 제 휴대폰 설계에 적용할 수 있도록 정량적 설계 요소로 변 환이 가능한 세부 감성을 실험 대상 감성으로 선정하였다. 이는 [1] 열 때 힘의 느낌, [3] 밀려 올라가기 시작하는 시 점 느낌의 2개이다. 즉, [5]의 마찰 느낌과 [6]의 완전히 열 리는 순간의 느낌은 설계 요소로 변환이 어려운 요소이다.

그리고 이들 감성과 Sliding Force Graph 상에서 직접 연 관된 Factor는 Open Max Force와 Dead point Ratio가 된
다. Open Max Force는 사용자가 상판을 밀어 올리는 동안 느낄 수 있는 최대힘이므로 이를 열 때의 힘으로 느끼게 된 다. Dead point Ratio는 사용자가 상판을 밀어 올리다가 어 느 시점부터 손에서 떨어져 자동으로 올라가는 지점(Dead point)의 전체 길이 대비 비율이므로 이를 밀려 올라가기 시 작하는 시점의 느낌으로 정의할 수 있다.

두 개의 Factor에 대한 실제값을 파악하기 위하여, 31개 의 슬라이드폰 가운데서 만족도가 평균 이상(3.5점 이상)인 16 개 제품을 대상으로 Factor 값을 측정하였다. 그 결과는 Table 1과 Table 2에 나타내었다. 또한 해당 모델에 대한 Factor 측면의 만족도도 같이 표시하였다.

Table 1. Open max force and Satisfaction score

\begin{tabular}{c|c|c}
\hline Model & Open Max Force & Open Max Force 만족도 \\
\hline A & 308 & 5.0 \\
\hline B & 264 & 4.6 \\
\hline C & 295 & 5.1 \\
\hline D & 309 & 5.0 \\
\hline E & 294 & 4.8 \\
\hline F & 395 & 4.1 \\
\hline G & 300 & 4.9 \\
\hline H & 260 & 4.8 \\
\hline I & 530 & 4.1 \\
\hline J & 253 & 5.3 \\
\hline K & 482 & 3.9 \\
\hline L & 412 & 4.0 \\
\hline M & 222 & 4.8 \\
\hline N & 373 & 4.1 \\
\hline O & 275 & 4.6 \\
\hline P & 314 & 4.6 \\
\hline
\end{tabular}

Table 2. Open max force and Satisfaction score

\begin{tabular}{c|c|c}
\hline Model & Dead point Ratio & Dead point Ratio 만족도 \\
\hline A & 58.5 & 4.48 \\
\hline B & 56.8 & 3.64 \\
\hline C & 56.3 & 4.87 \\
\hline D & 58.1 & 4.29 \\
\hline E & 56.8 & 4.80 \\
\hline F & 67.7 & 4.20 \\
\hline G & 60.0 & 4.58 \\
\hline H & 58.5 & 4.87 \\
\hline
\end{tabular}


Table 2. Open max force and Satisfaction score (Continued)

\begin{tabular}{c|c|c}
\hline Model & Dead point Ratio & Dead point Ratio 만족도 \\
\hline I & 59.9 & 4.73 \\
\hline J & 62.5 & 4.50 \\
\hline K & 57.2 & 3.93 \\
\hline L & 65.7 & 4.40 \\
\hline M & 56.2 & 4.16 \\
\hline N & 63.7 & 4.19 \\
\hline O & 59.5 & 4.42 \\
\hline P & 67.2 & 4.25 \\
\hline
\end{tabular}

이 결과로부터 1 차적으로 다음과 같은 1 차 결과를 얻을 수 있다.

1) $\mathrm{OMF}$ (Open Max Force)는 대략 250 300g/f에서 슬라 이드폰의 조작감 만족도가 높다(최소 $222 \mathrm{~g} / \mathrm{f}$ - Model $\mathrm{M}$, 최대 530g/f - Model I).

2) $\mathrm{DPR}$ (Dead point Ratio)은 55 65\%에서 슬라이드폰의 조작감 만족도가 높다(최소 $56.2 \%$ - Model M, 최대 $67.7 \%$ - Model F).

그런데 이 값들은 기존의 개발된 슬라이드폰들로부터 얻 은 값들이므로 슬라이드 조작감에 대한 완전한 최적값이라 고 보기 어렵다. 다시 말하면, Open Max Force가 대부분 $200 \mathrm{~g} / \mathrm{f}$ 이상이고, Dead point Ratio가 $50 \%$ 이상인 슬라 이드폰들을 대상으로 실험하였기에 $100 \mathrm{~g} / \mathrm{f}$ 나 $40 \%$ 의 값에 대해서는 조작감 평가가 되지 않은 것이다. 따라서 더 넓은 Factor의 값이 주어진 상태에서 조작감 평가 실험을 해야 그 결과가 진정한 최적값이라고 할 수 있다.

\subsection{Evaluation system development}

4.3 의 결과로부터 도출한 가정을 검증하면서 제약사항을 극복한 이상적인 최적값 도출 실험을 위하여 슬라이딩 조작 감 평가 시스템을 개발하였다.

이 시스템은 아래와 같이 3 개의 파트로 구성된다.

\subsubsection{Variable Stiffness Slide Device(VSSD)}

실제 슬라이드폰의 형태를 가지고 있으며, 사용자가 계획 한 강성 변화 특성을 물리적으로 느낄 수 있는 장치이다 (Figure 4). 상판의 위치 미소 변위량에 대한 출력 힘의 변 화량을 제어하는 방식의 메커니즘을 사용한다(Figure 5). 실험에 필요한 감성적 요소를 제외한 나머지 부분은 실제 슬 라이드폰과 동일해야 하므로, 질량과 재질, 외형, 그리고 동 작 형태 등을 그대로 유지하였다.
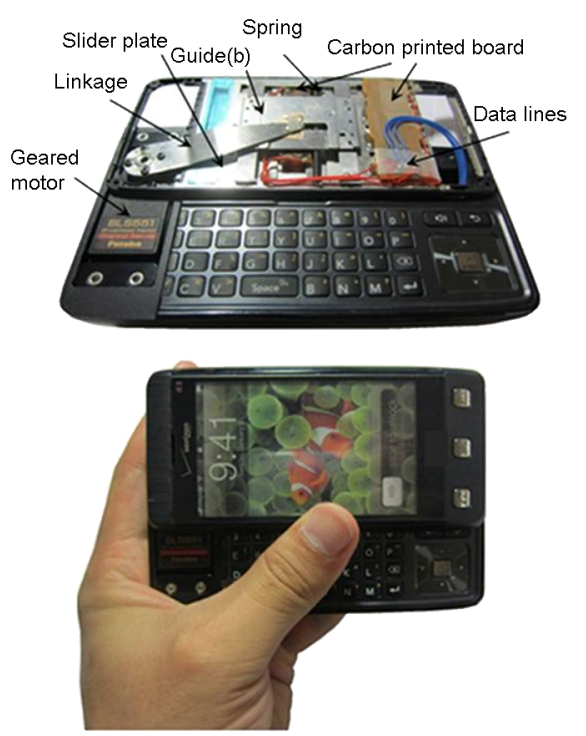

Figure 4. Internal view(high) and appearance(low) of the VSSD

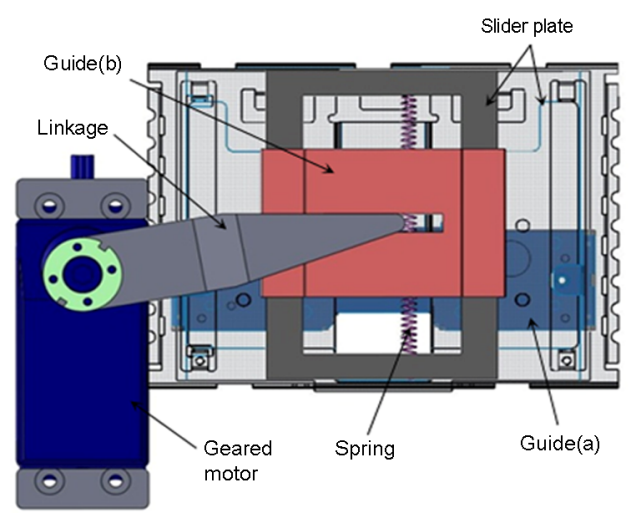

(a) Top view

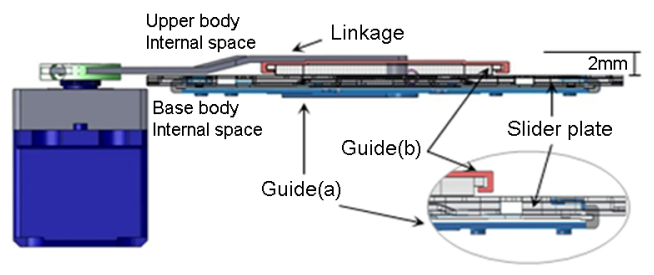

(b) Side view

Figure 5. Key component of VSSD

\subsubsection{Force control system}

제어 알고리즘을 고속 이산화 및 연산하기 위한 Digital Signal Process System이며, 전력 공급 회로와 제어 회로, 그리고 통신 회로부로 구성되어 있다. 사용자가 계획 완료한 
강성 변화 특성 데이터를 본 시스템으로 입력 받아, VSSD 를 통해 물리적 형태로 변환시키는 역할을 한다(Figure 6).

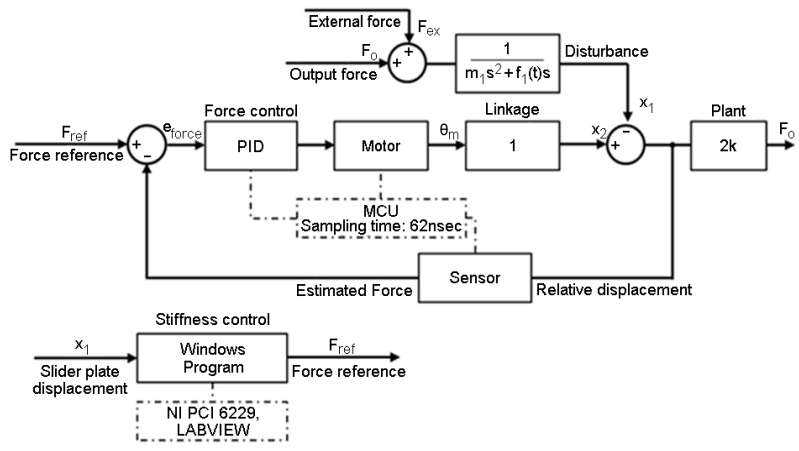

Figure 6. Control system scheme

\subsubsection{Stiffness control program}

사용자가 원하는 강성 변화 특성을 계획하고 운영할 수 있도록 개발된 User interface 프로그램이다. 계획 완료된 강성 변화 특성 데이터는 Force Control System에 입력되 며, 시스템 구동 명령 직후 사용자는 $\mathrm{VSSD}$ 의 조작을 통하 여 물리적으로 변환된 강성 변화 특성을 느낄 수 있다. 그 리고 작동 명령과 동시에 발생되는 데이터를 기록하여, 사 용자의 감성적 요소값을 도출하는데 사용할 수 있도록 한다 (Figure 7,8).

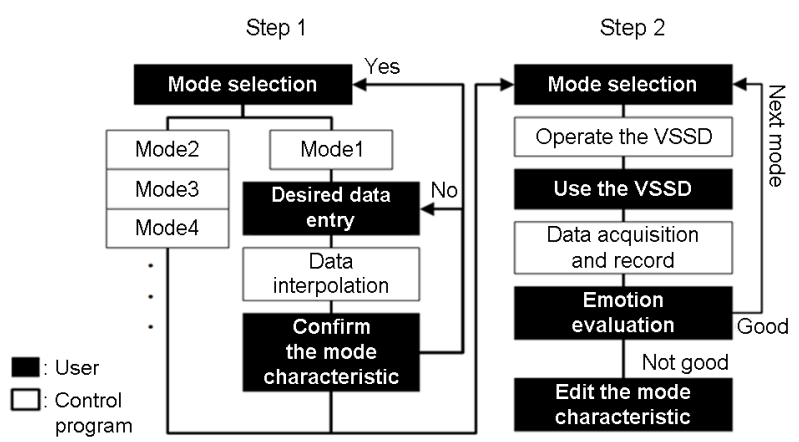

Figure 7. Flowchart of stiffness control system

\subsection{Optimal value extraction}

\subsubsection{Design of experiment}

기존 슬라이드폰에서 구현되지 않는 Factor의 값들까지 실험값에 포함시키기 위하여 4.3절에서 도출되어 1 차 결과 값들을 중심으로 범위를 넓혀 실험값을 선정하였다. 그리고 실험값들 간의 간격은 JND (Just Noticeable Difference)

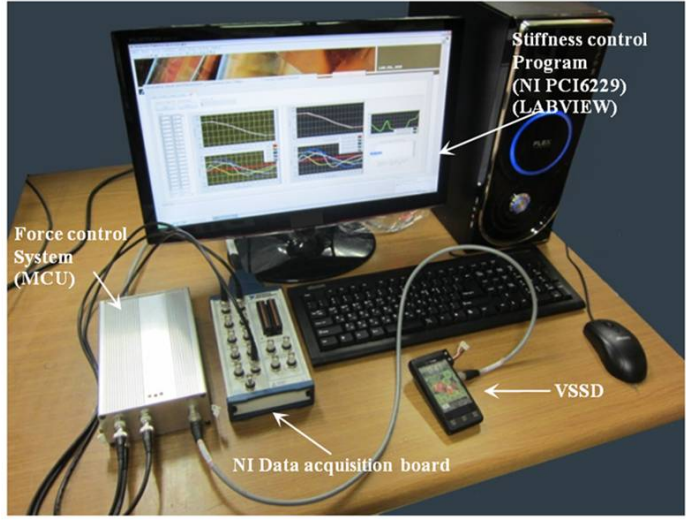

Figure 8. Integrated full system

와 실험 진행 시의 피실험자 정신적 부하를 고려하여 결정 하였다.

a. OMF: 만족도 높은 것으로 나타난 250 300g/f를 중심 으로 최소 $100 \mathrm{~g} / \mathrm{f}$ 와 최대 $400 \mathrm{~g} / \mathrm{f}$ 로 $50 \mathrm{~g} / \mathrm{f}$ 씩 증가시키 는 값을 선정하였다.

b. DPR: 만족도 높은 55 65\%를 중심으로 최소 $30 \%$ 와 최대 $70 \%$ 로 $10 \%$ 씩 증가시키는 값을 선정하였다.

\subsubsection{Experiment execution}

20 30대의 슬라이드폰 사용자 30명(평균 연령 28.8세) 이 실험에 참여하였다. 각 피실험자는 $\mathrm{OMF} 6$ 가지와 $\mathrm{DPR}$ 5 가지에 대하여 7 점 척도로 만족도를 평가하였다. 피실험자 간 순서효과를 제거하기 위하여 15 명은 DPR을 먼저 수행하 고 나머지 15명은 $\mathrm{OMF}$ 를 먼저 수행하였다. 또한 $\mathrm{DPR}$ 과 $\mathrm{OMF}$ 내에서도 Random 순서로 진행하였다. 그리고 만족도 평가 시 다른 Factor의 간섭에 의한 오염을 없애기 위하여 실험 외 Factor는 1개로 고정하였다. 즉, $\mathrm{OMF}$ 평가 시에는 $\mathrm{DPR}$ 을 가운데 값인 $50 \%$ 로 고정하였으며, $\mathrm{DPR}$ 평가 시에 는 $\mathrm{OMF}$ 값을 역시 실험 설계값 6 개의 평균인 $275 \mathrm{~g} / \mathrm{f}$ 로 고정하였다.

\subsubsection{Experiment result}

이상의 실험 결과에 대하여 One-Way ANOVA를 통해 해당 Factor 값 간 만족도 차이가 유의한 지 그렇지 않은지 를 확인하였다. 분석에는 SPSS v12를 사용하였으며, Tukey HSD Test로 유의한 차이가 나는 값들을 Grouping 하였다.

\section{Open Max Force(OMF)}

6 개 값들 간 $\mathrm{ANOVA}$ 결과 $p$-value $=0.000$ 으로 유의 한 차이가 있는 것으로 나타났다. 그리고 Tukey HSD Test 결과 Table 3 과 같이 $200 \mathrm{~g} / \mathrm{f}$ 와 $250 \mathrm{~g} / \mathrm{f}$ 가 높은 점수로 유의 
한 차이를 보였다. 즉, $\mathrm{OMF}$ 의 최적값 구간은 200 250g/f 이라 할 수 있다. 상대적으로 낮은 힘으로 열 수 있는 $150 \mathrm{~g} / \mathrm{f}$ 의 경우 너무 가볍게 열려서 튼튼한 느낌이 들지 않 는다는 실험 참여자들의 의견이 반영되어 점수가 낮아졌음 을 알 수 있었다. 그리고 $300 \mathrm{~g} / \mathrm{f}$ 가 넘어가면 상판을 밀어 올릴 때 손에 걸리는 힘이 부담스러워지고 결과적으로 슬라 이딩 만족도가 떨어짐을 알 수 있었다. Figure 9에는 결과 를 Graph로 표시하였으며 200 250g/f에서 만족도가 높음 을 직관적으로 알 수 있다.

Table 3. Force Satisfaction score

\begin{tabular}{c|c|c|c|c}
\hline \multirow{2}{*}{ Force } & \multirow{2}{*}{$\mathrm{N}$} & \multicolumn{3}{|c}{ Subset for alpha $=.05$} \\
\cline { 3 - 5 } & & 1 & 2 & 3 \\
\hline 350 & 30 & 2.9333 & & \\
\hline 400 & 30 & 2.9667 & & \\
\hline 300 & 30 & 3.3667 & 3.3667 & \\
\hline 150 & 30 & & 4.1000 & 4.1000 \\
\hline $\mathbf{2 5 0}$ & $\mathbf{3 0}$ & & & $\mathbf{4 . 5 3 3 3}$ \\
\hline $\mathbf{2 0 0}$ & $\mathbf{3 0}$ & & & $\mathbf{4 . 6 3 3 3}$ \\
\hline
\end{tabular}

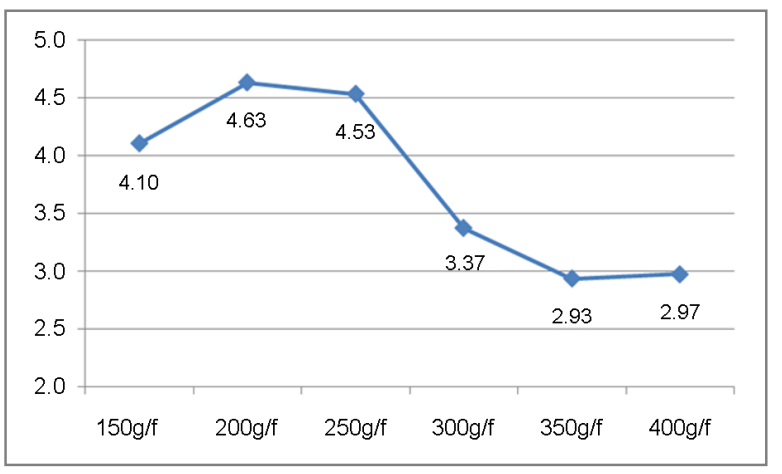

Figure 9. Force Satisfaction score

$\underline{\text { Dead Point Ratio (DPR) }}$

5 개 값들 간 ANOVA 결과 $p$-value $=0.000$ 을 역시 유 의한 차이가 있는 것으로 나타났다. 그리고 Tukey HSD Test 결과 Table 4 와 같이 $40 \%$ 와 50\%가 높은 점수로 유 의한 차이를 보였다. 즉, $\mathrm{DPR}$ 의 최적값 구간은 40 50\%이 라 할 수 있다. $30 \%$ 의 경우 살짝만 밀어도 밀려 올라가 버 려서 장난감 같고 실수로 열리는 경우가 많을 것 같다는 의 견이 반영되어 점수가 낮아졌음을 알 수 있었다. 또한 $60 \%$ 가 넘어가면 너무 길게 밀어야 하므로 만족도가 떨어짐을 알 수 있었다. Figure 10에는 결과를 Graph로 표시하였으
며 40 50\%에서 만족도가 높음을 직관적으로 알 수 있다.

Table 4. Ratio Satisfaction score

\begin{tabular}{c|c|c|c|c}
\hline \multirow{2}{*}{ Ratio } & \multirow{2}{*}{$\mathrm{N}$} & \multicolumn{3}{|c}{ Subset for alpha $=.05$} \\
\cline { 3 - 5 } & & 1 & 2 & 3 \\
\hline 70 & 30 & 2.6667 & & \\
\hline 60 & 30 & 3.2000 & 3.2000 & \\
\hline 30 & 30 & 3.5333 & 3.5333 & 3.5333 \\
\hline $\mathbf{5 0}$ & $\mathbf{3 0}$ & & $\mathbf{4 . 0 6 6 7}$ & $\mathbf{4 . 0 6 6 7}$ \\
\hline $\mathbf{4 0}$ & $\mathbf{3 0}$ & & & $\mathbf{4 . 3 3 3 3}$ \\
\hline
\end{tabular}

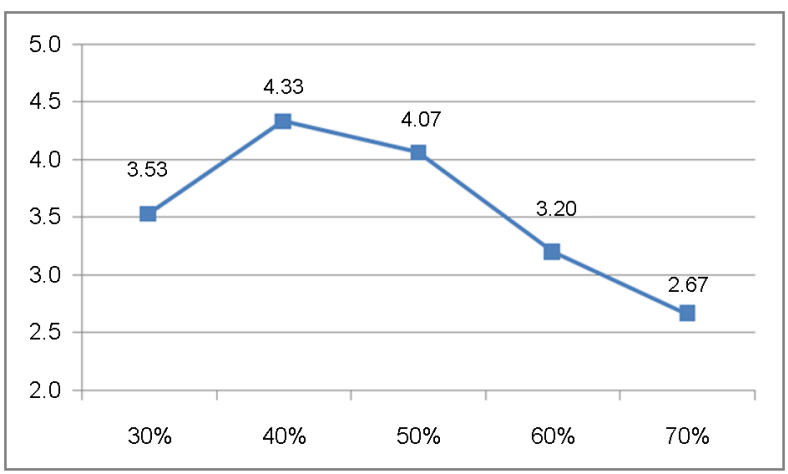

Figure 10. Ratio Satisfaction score

\section{Conclusion}

본 연구에서 sliding type phone에 대한 최적의 슬라이딩 감을 구현할 수 있는 설계 factor 값을 도출하기 위하여 이 를 구현할 수 있는 평가 시스템을 개발하고 그로부터 최적의 point를 발굴함으로써 정확한 만족 factor 값을 제공하였다. 즉, 다양한 관련 Factor 가운데서 critical factor는 Open Max Force와 Dead point Ratio였다. 그리고 Open Max Force의 최적값은 200 250g/f, Dead point Ratio는 40 $50 \%$ 였다.

본 연구는 기존의 이미지에 의한 감성 평가로는 값을 찾기 어려운 기구적 설계값을 발굴하기 위한 사례로 볼 수 있다. 특히 이를 위하여 기존의 제품들을 평가 대상으로 할 때의 제한적 값이 도출되는 한계를 극복하기 위하여 다양한 factor 값을 구현할 수 있는 시스템은 직접 제작하여 평가하고 값을 도출한 데 의미가 있다 하겠다. 이러한 방법은 다른 기구적 감성 도출 실험에 활용한다면 보다 실제적이고 제품 설계에 
바로 적용할 수 있는 Data를 얻을 수 있을 것이다. 또한

기존의 일반 sliding type phone은 물론 qwerty type의 smart phone 개발 시 기구 관점 개발의 기준으로 활용될 수 있다.

\section{References}

Jang Woo Jung, "Development for Evaluation Model of Click Sensibility in Cellular Phone", Doctoral Thesis, Myongji Univ., 2010.

Kim, I. K., Lee, C. and Yoon, M. H., "A Comparison of Modeling Methods for a Luxuriousness Model of Mobile Phones", Journal of the Ergonomics Society of Korea, 25(2), pp.161-171, 2006.

Koohyoung Lee, "Design: Between Technology and Market", World Congress on Environmental Design for the New Millennium Cultural Design, 2000

Min woo Hwang and Heon bae Jeong, "Study on the Emotional Consumption Value - Focused on the Relationship among Consumer Innovativeness, New Product Adoption and Emotional Consumption Value's Components", Journal of Advertising, Winter, 2007.

Min Soo Kim, Sung Woon Cha, Kyung Soo Lee and Hyun Seung Cho, "Emotion and Sensibility Engineering Appraisal Methodology for Selecting Form Factor in Early Mobile Phone Design", Korean Journal of the science of Emotion \& sensibility, 9(1), pp.27-38, 2006.

Myung Hwan Yun, Sung H. Han, Sang W. Hong and Jongseo Kim, "Incorporating user satisfaction into the look-and-feel of mobile phone design", Ergonomics, 46(13-14), 2003.

Sang Hoon Jeong, "Measuring user's emotions while using a cellular phone", Korean Society for Emotion \& Sensibility, 11(2), pp.215 $-226,2008$.

Sang Woo Ban, Il Sun Yu, Ga Won Kim, Byung Gi Jin and Yoon MH, "An Optimization of a Slide Cover for Mobile Devices, Korean Institute of Industrial Engineers/The Korean Operations Research and Management Science Society, Spring Conference, 2010.

\section{Author listings}

Jaein Lee: inibest@naver.com

Highest degree: $\mathrm{PhD}$, Department of Industrial Engineering, KAIST

Position title: Chief Research Engineer, Production Research Institute, LG Electronics

Areas of interest: Emotion \& Usability Related to Product, Human Error

Jungwoong Byun: chonju2001@korea.ac.kr

Highest degree: Master's degree, Control and Instrumentation Engineering, Korea University

Position title: Research Engineer, Production Research Institute, LG Electronics

Areas of interest: Actuators, Control algorithms, Precision systems

Jaehwa Jeong: jaehwa@korea.ac.kr

Highest degree: Ph.D, Department of Mechanical Engineering, KAIST Position title: Associate Professor, Department of Control and Instrumentation Engineering, Korea University

Areas of interest: Design and control of precision system

C. J. Lim: scjlim@kpu.ac.kr

Highest degree: $\mathrm{PhD}$, Department of Industrial Engineering, KAIST Position title: Associate Professor, Dept. of Game and Multimedia Engineering Korea Polytechnic University

Areas of interest: Game Interface Design, AR/VR UI/UX

Date Received : 2012-05-14

Date Revised : 2012-09-24

Date Accepted : 2012-09-28 